different, if allied, composition side by side in one bladder;" and he suggested, in explanation, "that in all probability, after one stone had developed, a slight change in diathesis occurred, and a fresh nucleus of another kind had cescended from the kidney and grew also," and he mentioned "that on several occasions, during lithotomy, he had found a large and a very small stone together, and during lithotrity by the old method the patient would have a distinct attack of renal colic and discharge an entire stone."

East Rudham, Norfolk.

\section{A CASE OF LANDRY'S PARALYSIS.}

BY W. E. BUCK, M.A., M.D. CantaB., PHYSICIAN TO THE LEICESTER INFIRMARY.

I venTuRe to publish the following scanty notes of a case which $I$ believe to be one of acute ascending paralysis, as first described by Landry in 1869. I desire to direct attention to it as a disease which is by no means easy to diagnose, and which sometimes is rapidly fatal. This paralysis has not, till recently, been noticed in the larger text-books on medicine, and very little is known about its etiology, and absolutely nothing about its pathology. Dr. Bristowe says that no morbid changes have been discovered which can account for the symptoms, and that in many cases the cord has been found apparently in quite a healthy state. These statements are confirmed by most other writers on the subject.

"Dec. 3rd.-Miss $\mathrm{R}$ - aged twenty, seamstress, says she has been feeling poorly for three weeks, and got her feet wet on Dec. 1st. She complains of a feeling of pins and needles, and want of power in the hands and feet. She walks lame, and cannot hold a cup or thread a needle. There is no swelling, redness, or tenderness. She says she does not feel ill.-4th: The patient developed a clicking in the throat last night; she had a good night, but cannot raise herself in bed nor stand this morning. Temperature normal. I was called to see her this evening, and went at 7.45. I found her much altered in appearance; complexion waxy, but not altogether pallid; a tinge of blueness round the lips. She was propped up high in bed. There was a continued rattling of mucus in the trachea, and an inability to speak loudly; there was also a feeling of choking and difficulty in swallowing, although she could swallow small quantities at a time. Bowels open several times. Pulse feeble, and feeling as if it might soon cease. At 9.30 she died without a struggle."

These notes were kindly given to me by Dr. CoxHippisley, Miss R-'s medical attendant. When he called me in to see her about an hour before her death she was propped up in bed and answered my questions rationally. She could not move her legs or her fingers, but could move her arms slightly. There was no ankle clonus, but I did not test for other reflexes. Her breathing was feeble and shallow, with a slight rattling of mucus in the trachea and bronchi. There were no other physical signs. Heart sounds normal, but feeble. No trouble as regarded bladder or rectum. Tongue clean; pupils dilated. Temperature normal; pulse normal, but feeble. She died apparently from some pressure or interference with the nuclei of the pneumogastric nerves-in fact, from bulbar paralysis.

I obtained permission to examine the body, and made the necropsy about forty hours after death. The body was exceedingly well nourished and well formed. Heart, lungs, stomach, and liver normal. The kidneys had the capsules thickened and were slightly contracted. The spinal cord was removed and hardened for microscopical examination, but nothing abnormal could be detected. This disease is mainly characterised by negatives in regard both to diagnosis and pathology. It is generally fatal, and may be of very short duration. In this case the patient did her work to within three days of her death, and even went to the theatre on the third evening before she died. The symptoms were in accordance with those usually described, except in one particular-viz., that she did not notice the loss of power first in the lower extremities and then gradually ascending. Dr. Bristowe, however, remarks, in the fifth edition of his "Theory and Practice of Medicine," that in some rare cases the paralysis takes a descending course, beginning above and involving the lower extremities last. This disease is not at all common, and the literature relating to it is so recent and scanty that I fancy it is not at all well known to the general profession; for these reasons I have thus briefly described this case, in the hope that more attention may be devoted to it. Leicester.

\section{NOTE ON THE}

\section{TREATMENT BY SECTION OF' HYDROCELE} BY THE ANTISEPTIC METHOD.

\author{
BY EDWARD BELLAMY, F.R.C.S.,
}

FELLOW OF KINA'S COLLEGE, SURGEON TO THL CHARIN(')-CROSS HOSPITAL EXAMINER IN SURGERY IN THE VICTORIA UNIVLRSITY, MANCHESTER.

THJ few remarks I make are based upon the results of a considerable number of cases I have treated, both in hospital and in private practice, in the early and later stages of hydrocele, by which latter I mean those which have been repeatedly tapped and in most instances injected. It is hardly necessary to take up space by instancing the individual cases. It is certainly time that the old-fashioned method of tapping and the supposed radical cure by continuous injection was done away with, as painful, dilatory, and generally useless. I claim no originality whatever in this treatment. I desire to call the attention of practitioners to the fact that they should invariably adopt the method of free incision with strict antiseptic precautions, and I cannot understand why it is not more universally carried out. Every surgeon knows of the method, but, as far as I see, contents himself with adhering to the usual proceedings. There is no danger in it. An anæsthetic can be given if necessary, the healing is rapid, the cure almost certain, if not absolutely so. The operation is as follows. The diagnosis of course being established, the scrotum should be shaved, and (if the surgeon thinks necessary) the spray used, the tumour is firmly grasped so as to render the parts as tense as possible. A clean sweep through all the scrotal tissues is then made with the bistoury from the cord to the base, and the fluid escapes. Every bleeding vessel, however small, must be twisted or tied most scrupulously, and the interior of the sac carefully examined for any vessel which may have been wounded or have given way. The cavity should then, not too tensely, be stuffed with either lint soaked in 1 in 40 carbolised oil or gauze, and the upper part of the edges of the wound stitched together, including all tissues - I do not see any advantage in stitching the cut edges of the sac to the sides of the wound,a small tag of the contents being left out of the most dependent part on the contingency of drainage, a pad of salicylic wool placed over all, and the scrotum supported by a cushion between the thighs. In a couple of days the parts may be dressed (under spray, if thought desirable) and the contents of the sac withdrawn. As a rule considerable contraction of the walls of the sac will have set in, but it is advisable to still introduce the antiseptic material so long as any appreciable cavity exists, and this is generally for about a week in very favourable cases, when it will be found impossible to pass anything into it, and merely the lips of the original wound are left to close. Tubal drainage is, I venture to think, unnecessary. I have not yet met with any untoward constitutional symptoms by adopting this method, which is equally applicable to encysted hydrocele of the cord. Wimpole-street, $\mathrm{w}$.

\section{A R E M A K A B L E C A S E.}

BY JAMES II. AVELING, M.D.,

SENIOR PHYSICIAN TO THE CHELSEA HOSPITAL FOR WOMEN.

The patient whose case is here briefly narrated is a married lady aged thirty-eight, with a family. She is very intelligent, and has no history of hysteria or other nervous disorders. In October, 1884, one of her children struck her left eye with the back of his head. Six weeks after she felt something wrong with the eye. She also had noises in the ears, and tenderness of the nose, and pain at the back of the head when she stooped or had the bowels moved. Her speech also was affected. She hesitated and stammered when she spoke. These symptoms lasted and gradually got 